\title{
Organizaciones armadas post Autodefensas Unidas de Colombia: Del pasado contrainsurgente al presente de criminalidad transnacional. 2006-2016
}

Armed organizations past United self Defense: From the counterinsurgent past to the present of transnational criminality. 2006-2016

Patricio García Pérez*

\begin{abstract}
Resumen: La investigación tiene como objeto de estudio las formas de violencia organizada de Colombia en el contexto de las mutaciones del conflicto interno y de los actores paraestatales que lo han protagonizado, luego de la desmovilización parcial de las Autodefensas Unidas de Colombia el año 2006 y hasta el año 2016. La pregunta vital consiste en sistematizar diferencias en las organizaciones que irrumpen tras las AUC, ¿eran una continuidad paramilitar?, ¿o tenían elementos distintos? El trabajo conceptualiza históricamente a las entidades criminales como partes de la evolución de la privatización de la violencia colombiana, cuyas modalidades para institucionales han estado presentes desde los años 50. Se exponen, los principales debates acerca del paramilitarismo en Colombia, debido a la complejidad del tema. Como hipótesis de trabajo se establece que, en conflictos internos extendidos como el colombiano, las fragilidades y debilidades institucionales sumado al incremento de economías ilegales producen la transformación de organizaciones paraestatales y paramilitares partes del conflicto, con elementos políticos contrainsurgentes en formaciones predominantemente criminales.
\end{abstract}

Palabras clave: Capitalismo criminal, paramilitarismo, actor delincuencial transnacional, posconflicto, actores paraestatales.

Abstract: The following research has as object of study the forms of organized violence of Colombia in the context of the internal conflict mutations and the parastatal actors that have played a leading role, after the partial demobilization of the United Self-Defense Groups of Colombia (AUC) in 2006 and until the year 2016. The vital question is to systematize differences in the organizations that burst after the AUC, were they a paramilitary continuity? Or did they have different elements? The work historically conceptualizes criminal entities as part of the evolution of the privatization of Colombian violence, whose modalities for institutions have been present in the past since the late 1950s. The main debates about paramilitarism in Colombia are exposed, as necessary, due to the complexity of the subject. As a working hypothesis it is established that in extended internal conflicts like the Colombian case, the institutional weaknesses and fragilities added to the increase of illegal economies produce the transformation of parastatal and paramilitary organizations which are parts of the conflict, with counterinsurgent political elements in predominantly criminal formations.

Keywords: Criminal capitalism, paramilitarism, transnational criminal actor, postconflict, parastatal actors.

Recibido: 24 agosto 2018 Aceptado: 9 octubre 2018

\footnotetext{
* Chileno, Profesor, Licenciado, Magíster y Doctor en Historia, Departamento de Historia, Universidad de Santiago de Chile, patricio.garcia.p@usach.cl Agradecimientos al Proyecto POSTDOC_DICYT, Código 031752GD, Vicerrectoría de Investigación, Desarrollo e Innovación, Universidad de Santiago de Chile, USACH
} 


\section{Introducción}

La investigación tiene como escenario histórico el extenso conflicto colombiano, caracterizado por su heterogeneidad, intensidad variable, diversidades en el repertorio de la violencia y desde de los años 90, protagonizado por el paramilitarismo (fuerzas paraestatales), las guerrillas (contraestatales) y las fuerzas del Estado ${ }^{1}$.

El objeto de estudio, radica en la evolución histórica de la privatización de la violencia de tipo paraestatal desde las Autodefensas Unidas de Colombia, (AUC), hasta las organizaciones criminales que irrumpen en el año 2006, una vez ocurrida la desmovilización del Bloque "Elmer Cárdenas" de Urabá.

Estos grupos armados post AUC, estaban integrados por antiguos miembros de dicha organización y su interés primordial era el control de actividades económicas de alta rentabilidad, como la cadena productiva del narcotráfico, la minería del oro y el contrabando. En esta investigación, se analiza el carácter de actor económico y el accionar transnacional de las organizaciones más grandes, como evolución de la privatización de la violencia de Colombia.

Se trata de una variedad de grupos criminales, tales como bandas, pandillas, combos, facciones del paramilitarismo, oficinas de cobro, ejércitos irregulares y disidencias guerrilleras. Además, operan con una gran diversidad de nombres, Urabeños, Caparrapos, Rastrojos, Puntilleros, Pelusos, Pachenca, Resistencia Wayuú, Erpac, Águilas Negras, La Oficina, Gaitanistas, entre muchos otros, localizados en los ámbitos rurales o urbanos y han sido denominadas de modos distintos como "bacrim", GAO, GDO desde el Estado, "narcopamilitares" o "grupos armados posdesmovilización" entre otros, en el mundo académico. Todo ello habla de la complejidad del objeto de estudio.

Consideramos como hipótesis, que los conflictos armados de carácter interno extendidos en el tiempo, acompañados de fragilidades y fallas institucionales ${ }^{2}$, unido al incremento de las economías ilegales, producen la transformación de organizaciones paraestatales de componentes insurgentes o contrainsurgentes en formaciones armadas predominantemente criminales ${ }^{3}$ movilizadas en pos del logro de beneficios económicos de sus integrantes a partir del control de las actividades productivas y su comercialización a escala transnacional.

Es para analizar en otro trabajo, lo que ocurre con una parte de la antigua guerrilla de las FarcEP una vez desmovilizadas a través de los acuerdos de paz del año 2016 con el Gobierno de Juan Manuel Santos. Al correr de las semanas, fue siendo cada vez más notoria la existencia de disidencias en la organización. Al "Frente Primero" del Putumayo se fueron sumando otras estructuras y dirigencias (Gentil Duarte), los cuales han desarrollado actividades de tipo delictivo (por ejemplo, en la frontera con Ecuador), vinculado al control de actividades económicas ilegales.

Como base historiográfica y marco teórico el trabajo se inscribe dentro de la "Historia de las Relaciones Internacionales". Utilizamos la consideración, análisis y descripción de esta línea historiográfica acerca de los "actores delincuenciales transnacionales", como partes del orden global, como una adecuación actualizada del concepto de "fuerzas profundas" de Renouvin y Durouselle",

\footnotetext{
1 Medina Gallego Carlos y Téllez Ardila "La violencia Parainstitucional, paramilitar y parapolicial en Colombia” Rodríguez Quito Editores, Bogotá Colombia, 2004. También en Palacios Marco "Violencia pública en Colombia 1958-2010 "Capítulo III "Guarra a las drogas, escalamiento y guerra sucia" Fondo de Cultura Económica, Bogotá, Colombia, 2012.

2 En ningún caso consideramos a Colombia como una forma de "estado fallido". No es el caso en absoluto. Se trata de un Estado reconocido internacionalmente, que firma tratados de libre comercio, parte de la comunidad internacional, con poderes del estado elegidos por la población, aunque históricamente ausente en espacios de frontera donde la violencia germino. Sobre el tema se puede mirar Robinson James, "La Miseria en Colombia” Desarrollo social n 7, Jan/June 2016, Bogotá.

${ }^{3}$ Kaldor Mary "New and old wars organized violence in the global era" Polity Press Cambridge CB 21 UR, UK 2012.

4 Renouvin Pierre "Historia de las Relaciones Internacionales" Tomo I, Akal, España, 1990. Renouvin Pierre y Duroselle Jean Baptiste "La introducción a la Historia de las Relaciones Internacionales" Fondo de Cultura Económica, España, 2001.
} 
forjadores de esta área del trabajo académico. En esta investigación, las conceptualizamos como "fuerzas transnacionales".

El trabajo se divide en tres partes. La primera aborda la temática del paramilitarismo en la historia de Colombia, como una modalidad secular de privatización de la violencia y sus principales referencias teóricas 5 . A continuación, se exponen los argumentos existentes entre el Estado y los centros académicos, organizaciones de derechos humanos, y organismos internacionales que conceptualizan a las organizaciones post AUC de modo distinto. Al mismo tiempo planteamos nuestra percepción en torno a este debate.

Posteriormente, se desarrollan las características de capitalismo criminalizado que las organizaciones desarrollan. Se exponen las bases productivas, impactos macroeconómicos, adecuaciones orgánicas y el carácter de actor trasnacional de las organizaciones. Se considera, sobre todo, a las entidades de mayor envergadura, como el "Clan del Golfo". Para su realización se ha revisado la más relevante bibliografía de tipo académico sobre el paramilitarismo, junto a las fuentes oficiales del Gobierno, la Policía Nacional, Fiscalía, los dictámenes de los Tribunales de "Justicia y Paz" acerca de las organizaciones criminales post AUC, e investigaciones académicas acerca del crimen organizado en la globalización. Se ha revisado también, la revista política "Semana", el diario "El Tiempo" y el portal "Verdad Abierta" a partir del año 2006 y hasta el 2017 entre las principales fuentes periodísticas.

\section{La privatización de la violencia y el Paramilitarismo en la historia reciente de Colombia ${ }^{6}$}

La privatización de la violencia ha estado presente en la historia de Colombia durante el siglo $\mathrm{XX}$, a lo menos desde la década de los 50. Desde entonces ha conocido procesos tanto de institucionalización en los años 60 con la ley 3398 y en 1994-95 con las llamadas "Convivir". Produjo así mismo, formaciones de autodefensas contrainsurgentes en la década de los 80 y paramilitares posteriormente, cuya mayor expresión fueron las AUC en abril de 1997. Debido al uso continuo en este trabajo del "paramilitarismo" como concepto clave es que exponemos algunos aspectos teóricos para dar a conocer la complejidad de este.

El paramilitarismo, no es un fenómeno colombiano ni latinoamericano, aun cuando en esta región hubo manifestaciones de gran intensidad de este fenómeno como las Patrullas Campesinas, PAC de Guatemala, las "Rondas Campesinas" o el Comando "Rodrigo Franco" de Perú por ejemplo. Existieron también organizaciones paramilitares en África y Europa en el siglo XX.7 Las "Autodefensas Unidas de Colombia", AUC, la mayor organización paramilitar de la historia colombiana, se constituyó como una forma organizada de ejercer la violencia, que aspiró a aglutinar jerárquicamente y federalizar estructuras de autodefensas repartidas en la fragmentada geografía colombiana, fue tributaria de la Guerra Fría, estuvo apoyado por partes del Estado y sostenida por élites locales y regionales refractarias a las reformas democráticas que impulsaba el Estado central y a las negociaciones de paz con la guerrilla desde mediados de los 80 . Al mismo tiempo, fueron capaces de levantar e impulsar una exitosa política de expansión territorial, apropiación y concentración de la tierra. ${ }^{8}$

\footnotetext{
5 Trejos, Kalyvas y Ana Arjona "Paramilitarismo una perspectiva histórica "en "El Poder Paramilitar "Alfredo Rangel Editor y prólogo, pp 25-41, Planeta Colombia, 2005.

${ }^{6}$ García Patricio "La privatización de la violencia en Colombia y las AUC: de las autodefensas al paramilitarismo criminal y contrainsurgente" Revista Izquierdas, N 27 abril de 2016 E-ISSN 0718-5049

7 Kalyvas Statis- Arjona Ana "Paramilitarismo: Una perspectiva histórica" en "El Poder Paramilitar" Alfredo Rangel edición y prólogo, pp. 25-41, Planeta, Bogotá 2005.

8 Gibson Edward "Subnational Authoritarianism Territorial Strategies of Political control in Democratic Regimes", Northwestern University, September 25, 2004 en López Claudia "Y refundaron la patria.... De cómo mafiosos y políticos reconfiguraron el Estado colombiano” Debate, Bogotá DC,Colombia, 2010.
} 
Desde el punto de vista político, desarrollaron un accionar que les permitió no sólo dominar el poder local y regional, sino que también ocupar una parte del Estado -el poder legislativo- y manejarlo en función de sus intereses 9 . Históricamente es posible ordenar su evolución en dos fases cualitativa y cuantitativamente distintas. La primera de ellas en Puerto Boyacá a mediados de los años 80 vinculada a los poderes económicos de ganaderos y a las fuerzas militares, para evolucionar más tarde a las AUC el año 1997 cercana al narcotráfico y a la dirección de poderosos "Señores de la guerra"10.

Los paramilitares han sido definidos de modo muy particular y en ocasiones se les ha confundido con autodefensas, escuadrones de la muerte o grupos de violencia privada de tipo criminal ${ }^{11}$. Para Fernando Cubides $^{12}$, al hablar de paramilitares se está haciendo referencia a grupos irregulares del Estado que buscan "sustituirlo en vez de tomar control de él", presentan ciertas dimensiones características, como el tamaño, pudiendo encontrarse desde vigilantes locales hasta ejércitos móviles, los que logran poder político, militar y económico que, como señalan Kalyvas-Arjona, siempre están ligados al Estado y su actividad central es la producción de violencia en todas sus formas: "Los paramilitares son grupos armados que están directa o indirectamente vinculados al Estado y sus agentes locales conformados por el Estado o tolerados por este, pero que se encuentran fuera de su estructura formal". ${ }^{13}$ Los ejércitos paramilitares, funcionaron desde fuera y en ocasiones desde dentro del espacio político del Estado, como con la llamada parapolítica, constituyendo una especie de "outsourcing" de la violencia estatal. Su existencia está siempre en relación a la construcción del Estado del país en que operan. Por cierto, los Estados fuertes no necesitarán privatizar la violencia, "o contratar a terceros", ya que pueden controlar de manera efectiva o reprimir las amenazas externas usando su aparato policial normal. En cambio, los Estados débiles deben afrontar estas amenazas internas apelando a la privatización y el "outsourcing" 28.

Para Gustavo Duncan ${ }^{14}$ el paramilitarismo de Colombia correspondió a formaciones armadas de "ejércitos privados al servicio de "Señores de la Guerra". Eran ejércitos privados de combatientes"15 que aseguraban por la fuerza y la coerción, en fin, el predominio de sus jefes sobre el poder local. En síntesis, teóricamente, las organizaciones paramilitares se caracterizan por su vinculación con el Estado, ya sea que este las tolere o promueva, poseen apoyo y redes de sustento en la sociedad donde operan, hacen gala de un discurso contrainsurgente y repertorios de violencia propios de la guerra sucia.

El paramilitarismo de los años 90 y las AUC, no configuraron "un levantamiento frente al Estado sino que respondió a agrupaciones armadas de surgimiento legal luego ilegalizadas pero no combatidas que hicieron parte de la lucha contrainsurgentes con relaciones o al menos permisividad de las fuerzas estatales"16. Se constituyeron en un tercer actor del conflicto armado entre los años 19972003 estableciendo una vinculación directa con el narcotráfico, sus fuerzas armadas y de seguridad. El control del comercio de la cocaína le deparó a la organización recursos económicos para sus operaciones armadas. Desde el punto de vista de su origen social sus integrantes provenían de estratos sociales medios y bajos de la ruralidad cercanos a lo que Hobsbawm denominó "la cofradía de los mayordomos"17.

\footnotetext{
9 López Claudia (Edición) "Y refundaron la Patria...De como mafiosos y políticos reconfiguraron el Estado colombiano" Corporación Nuevo Arco Iris, Congreso, Visible, De Justicia, Grupo Método, Bogotá, 2010.

10 Duncan Gustavo “Los Señores de la Guerra, De paramilitares, mafiosos y autodefensas en Colombia” Debate, Bogotá DC, Colombia 2010.

11 García Patricio "La privatización de la violencia en Colombia y las Autodefensas Unidas de Colombia, AUC: de las autodefensas al paramilitarismo contrainsurgente y criminal” Revista Izquierdas N 27 abril 2016 pág 230-255

12 Cubides Fernando "Los paramilitares y su estrategia", Ediciones Uniandes, Bogotá 1999, pp 151-159.

13 Kalyvas-Arjona Op. cit., pp 29-30

14 Duncan op. cit. Pp 330

15 Duncan op. cit. pp 335-337

16 “Basta Ya! Colombia: memorias de guerra y dignidad” Centro Nacional de Memoria Histórica pág.36 Bogotá, 2012.

${ }^{17}$ Hobsbawm Eric "Rebeldes Primitivos", Editorial Ariel, Barcelona, 1983.
} 
¿Hubo motivaciones políticas, contrainsurgentes, en el accionar de las AUC durante el período histórico que se extiende desde su fundación en 1997 y hasta la desmovilización del año 2006? Las evidencias indican, que hubo en una parte de la comandancia una estrategia de control del poder político. No bajo la forma de un proyecto ideológico, o en la formación de un sujeto político identitario (partido político) de quienes integraron la organización. Tampoco dio forma a un proyecto de tipo integral para Colombia. La organización, describió limitadamente su papel en la escena del conflicto interno como se reflejó en su declaración de principios fundacionales de abril del año 1997. Allí expusieron que, "Somos un movimiento político-militar de carácter antisubversivo en ejercicio del derecho a legítima defensa que reclama transformaciones en el Estado pero no atenta contra él"18.

El debate histórico acerca de los aspectos políticos en las AUC no ofrece resultados únicos. Por una parte, ha sido objeto de interés, trabajos y análisis del campo académico. Destacan en ese sentido, Jorge Luis Garay, Gustavo Duncan, Carlos Medina Gallego, Mauricio Romero, Claudia López, María Teresa Ronderos, Juan Carlos Garzón, y Ariel Ávila. En todos ellos, el planteamiento predominante es que la organización paramilitar constituyó una entidad armada que contó con distintos niveles de apoyo en las fuerzas del Estado, las elites ganaderas, y parte de la sociedad civil que habrían implementado un proceso de expansión territorial a partir del año 1998-2001 con metodologías violentas y propias de la guerra sucia contrainsurgente como las masacres. En otro polo del debate, Camilo Echandía rechaza el carácter contrainsurgente de las AUC, reinstalando la tesis de Germaine Tillon de los "enemigos complementarios". En este modelo los paramilitares y las guerrillas, justificaron su existencia en la confrontación, no obstante su objetivo era apoderarse de las redes del narcotráfico ${ }^{19}$.

En otro ámbito, en el plano jurídico, no se ha producido una sentencia unificada respecto a las motivaciones políticas de las AUC. En el contexto de la "Ley de Justicia y Paz" se han vertido dos sentencias importantes y contradictorias. La primera de ellas caracteriza a las AUC como una organización criminal y la segunda, la describe poseedora de elementos políticos contrainsurgentes.

En junio del año 2017, el Magistrado Eduardo Castellanos, a partir de 44 sentencias de" Justicia y Paz", basadas en el accionar de Indalecio Sánchez Jaramillo integrante del "Bloque Tolima" de las AUC, estableció que esta entidad "fue una alianza temporal e inestable de diferentes dueños de ejércitos privados regionales y narcotraficantes que convergieron a inicios del siglo XXI para aprovechar las ventajas del proceso de paz" ${ }^{20}$. Siete meses más tarde, el magistrado Fernando León Bolaños en Fiscalía 56 de "Justicia y Paz" daba por descartada la resolución del Juez Castellanos por contradictoria y anfibológica, es decir por utilizar palabras que permiten más de una interpretación. Señalaba que se había caracterizado al "Bloque Tolima" como una "oficina de cobros" propias de la mafia y el narcotráfico, mientras al mismo tiempo, se acusaba a Sánchez Jaramillo de crímenes de guerra $^{21}$.

Una parte del alto mando paramilitar, desplegó un plan de poder político, concertado, tendiente a hacerse de partes del Estado ${ }^{22}$ a nivel local, dando forma a lo que Duncan denominó "Santuarios Rurales"23. También, avanzaron en posiciones dentro del poder legislativo, con la finalidad de obtener beneficios económicos y jurídicos, más que para imponer sus principios ideológicos. Para la ejecución del plan, utilizaron las potencialidades político-militares de los Bloques y Frentes bajo su

18 García Patricio “Las Autodefensas Unidas de Colombia (AUC) 1994-2005 “.Historia de un actor estatal, antisubversivo y de alcance transnacional en el conflicto interno" Capítulo IV páginas 163-176,Tesis para optar al Grado de Doctor en Historia, Depto. de Historia, Universidad de Santiago de Chile, 2016.

19 Echandía Camilo "Narcotráfico génesis de los paramilitares y herencia de bandas criminales" Fundación Ideas para la Paz, 6 de febrero de 2013.

${ }^{20}$ www.verdadabierta.com "Las AUC fueron alianza criminal de ejércitos privados" 10 de junio de 2017.

21 En www.verdadabierta.com "Ponencia del Magistrado Fernando León Bolaños en Fiscalía 56 de Justicia y Paz contra la decisión tomada por la Sala de Justicia y Paz del Tribunal de Bogotá del 24 de enero 2018”.

22 Este proceso fue denominado como Captura y reconfiguración cooptada del estado en el trabajo de Garay.

${ }^{23}$ Duncan Gustavo "Señores de la Guerra" 
mando, al mismo tiempo que desarrollaron una estrategia de cooptación, convencimiento o sometimiento de políticos profesionales que sirvieron a sus intereses en los espacios institucionales referidos. Impulsaron un activo "clientelismo armado," tomando el control de esta modalidad de hacer política, e hicieron las veces de Estado en su ausencia, y también de empresariado.

En el plano ideológico, parte del alto mando de la organización (Carlos Castaño, Iván Duque, Rodrigo Tovar), hizo suyo un anticomunismo agresivo que junto a la defensa de la propiedad, del orden y las jerarquías sociales, en zonas rurales ${ }^{24}$, se convirtió en su eje doctrinario. Las influencias ideológicas, se desarrollaron internamente a través de integrantes como "Ernesto Báez" y Hernán Gómez. Pero, al mismo tiempo fueron inducidas desde fuera, partir de la relación con las fuerzas del Estado (Ejército), formadas hasta entonces, en la lógica del enemigo interno tributaria de la guerra fría 25 .

Otro modo de discutir sobre las motivaciones políticas de las AUC, es a partir de su accionar social. Este, les condujo a impulsar proyectos económicos, y acciones de clientelismo armado orientado a la captura del Estado y control de la población. Se pueden mencionar en ese sentido, las modalidades usadas para la conformación de estados $\operatorname{locales}^{26}$ controlados por paramilitares, como ocurrió en Urabá con el Bloque "Elmer Cárdenas" y el Comandante Freddy Rendón, "El Alemán". Este, era reconocido como la autoridad central en Urabá, desarrollo planes económicos con base en la explotación de la madera, echó a andar el proyecto "Promotores de Desarrollo Social", PDS, que buscaba revivir las "Juntas de acción comunal", la unidad más básica del sistema político colombiano, quienes realizaron el arreglo de puentes y caminos, escuelas, al mismo tiempo que despojaban con violencia la tierra a campesinos y población afrodescendiente ${ }^{27}$.

Estructuras de las AUC como el "Bloque Norte", desarrollaron la cooptación de políticos regionales $^{28}$, la acción de fuerza orientada a la intimidación o convencimiento de actores políticos conocido como parapolítica ${ }^{29}$, la intervención electoral y la financiación de campañas a cambio del acceso a recursos del estado local. Otra referencia para conceptualizar la acción política de las AUC, proviene del trabajo de Jorge Garay referido a la "captura y reconfiguración cooptada del Estado". Este concepto es definido como una forma de corrupción a gran escala, producido por la "acción de individuos, grupos o firmas que influyen en la formación de leyes, decretos y otras políticas de Gobierno para su propio beneficio" 30 . El año 2001, las AUC vivió su momento de mayor expansión nacional. En efecto, los paramilitares estaban presentes en el 35\% del territorio colombiano expresado en 49 frentes bélicos, 26 departamentos de los 32 del país, y 382 municipios ${ }^{31}$. Pero paradojalmente, experimentaban al mismo tiempo, una espiral de crisis interna potenciada por la presión internacional, las diferencias al interior de su comandancia y el poder del narcotráfico.

${ }^{24}$ Cepeda Iván- Rojas Jorge "A las puertas de El Ubérrimo, El origen del paramilitarismo y la parapolítica en Córdoba” Ediciones B Colombia S.A. 2014.

${ }^{25}$ En este aspecto controvertido resulta enriquecedor revisar la sentencia a José Miguel Narvaez, ex subdirector del DAS por el asesinato de Jaime Garzón en agosto de 1999 y su papel de ideólogo del paramilitarismo. También en Aranguren Mauricio "Mi confesión Carlos Castaño revela sus secretos” Editorial Oveja Negra, 2001, para el rol de Duque y Gómez en las AUC

26 García Patricio "Las Autodefensas Unidas de Colombia (AUC) 1994-2005 ".Historia de un actor estatal, antisubversivo y de alcance transnacional en el conflicto interno” Capítulo IV páginas 163-176,Tesis para optar al Grado de Doctor en Historia, Depto. de Historia, Universidad de Santiago de Chile, 2016.

27 www.verdadabierta.com "Declaraciones de Fredy Rendón Herrera en la "Diligencia declaratoria de Justicia y Paz junio 2014” / 41614 de octubre 2008. Ronderos María Teresa “Las Guerras Recicladas Una historia periodística del paramilitarismo en Colombia" pp. 274-275, Aguilar, Bogotá, Colombia, 2014,

www.semana.com "El Fuhrer de Urabá” Edición 1265 de 31 de julio 2006.

28 Idem, páginas 181-189.

${ }^{29}$ Importante información Giraldo Juan Carlos "Las Comadres de la Parapolítica” Editorial "Círculo de lectores", Colombia, 2016, que expone la acción política de las Senadoras Eleonora Pineda y Rocío Arias acusadas y sentenciadas por parapolítica.

30 Garay Salamanca Luis Jorge (Dirección académica) "La captura y reconfiguración cooptada del Estado en Colombia" Corporación Transparencia por Colombia 2008, pág.16. También en World Bank XV, 2000.

31 García Patricio op.cit pp 307 
Los factores de esta crisis fueron: el peso creciente de los narcotraficantes en los cargos de dirección ${ }^{32}$, la catalogación por parte del gobierno de G.W. Bush de las AUC como organización terrorista de acuerdo a la resolución 1373 de la ONU sumado a los cruentos enfrentamientos internos entre líderes de Bloques de la organización, que desmentían en los hechos el carácter de organización jerárquica de las AUC, y golpearon de modo definitivo su unidad y capacidad operativa. Tres ejemplos de esta lucha intestina, fueron los enfrentamientos armados del Bloque Metro con el "Cacique Nutibara" en Medellín, el "Bloque Norte de "Jorge 40” y Hernán Buitrago en Santa Marta, y la llamada "guerra de Los Llanos" que enfrentó a Martín Llanos y Miguel Arroyave en el Meta y Casanare, en el primer lustro del siglo XXI.

Los comandantes de las autodefensas, no tenían las mismas motivaciones para integrar la organización. Este hecho, lo constató Carlos Castaño cuando afirmó que "yo creo que algunos están aquí para fortalecer su patrimonio económico, otros quieren salir de la cárcel donde están detenidos por conductas ajenas a la causa"33, estas diferencias y enfrentamientos terminarían con la muerte del mismo Castaño en el marco del proceso de inicio de diálogos de paz con el Gobierno.

Para implementar las negociaciones en el marco institucional, el Presidente Uribe debió modificar la ley 418 que le impedía desarrollar procesos de negociación con actores fuera de la Ley como era el caso de los paramilitares. Promovió por ello la ley 782.

El 23 de noviembre del año 2003, el proceso tuvo su primer éxito con la desmovilización del "Bloque Cacique Nutibara" y 868 integrantes $^{34}$. Se institucionalizó el proceso, a través de la Ley 975 llamada de "Justicia y Paz", que fue publicada en el "Diario Oficial" de Colombia el 25 de julio del año 2005. Los datos oficiales señalan que entre el 2003 y el 2006 se desmovilizaron 36 estructuras de las AUC y 31.671 combatientes entregándose 18.051 armas. Tras ser recluidos en la cárcel de "La Ceja" el año 2006, el Presidente Uribe tomó la decisión de extraditar dos años más tarde, el 13 de mayo a los EEUU a los principales comandantes como Mancuso, Murillo, Vanoy, Jiménez, Buitrago entre otros.

\section{Organizaciones armadas post AUC 2006-2016: ¿Bandas criminales, GAO, GDO o continuidad paramilitar?}

Las primeras alertas en torno al fenómeno de reaparición de grupos armados organizados, provino del periodismo de opinión y denuncia. En reportajes ${ }^{35}$ se exponían las denuncias recogidas entre la población, debido al recrudecimiento de acciones violentas en departamentos del país que habían estado bajo el control y dominio de las AUC como Urabá o Córdoba. Se informaba asimismo, sobre una reunión del 30 de mayo del 2006, en el Ministerio de Defensa Colombiano de la Junta Nacional de Inteligencia en la cual se conoció un informe confidencial sobre el rebrote de la violencia y se enfatizó en que las organizaciones armadas emergentes buscaban "copar espacios dejados por los desmovilizados y hacerse a posiciones estratégicas en viejas zonas de conflicto" 36 . Para el Estado colombiano, las formas de violencia privada que emergieron en distintos departamentos y municipios, no correspondían a continuidades o nuevas formas de paramilitarismo. Se trataba de un fenómeno de carácter criminal, que por lo tanto debía enfrentársele a través del accionar policial, haciendo valer el monopolio de la fuerza estatal, y de la institucionalidad. El Gobierno de Uribe, estableció la denominación genérica de "Bandas Criminales "o Bacrim, ratificando su visión de que en Colombia no

32 El mejor ejemplo lo constituyo el nombramiento de Diego Murillo o "Don Berna" en el cargo de Inspector General de las AUC en esos años, ver Corporación Observatorio para la Paz, "Las verdaderas intenciones de los paramilitares", Anexo 27 "La verdad sea dicha" Páginas 352-358

33 Aranguren Mauricio op. cit. pp 307.

${ }^{34}$ www.verdadabierta.com "Así se fraguó el acuerdo de paz con los paras" 26 de abril del 2010.

35 Revista "Cambio", "Reciclaje Para” Edición Nº 676 del 12 de junio del año 2006.

36 Op. cit. 
existía un conflicto interno, sino una guerra contra el terrorismo y los grupos ilegales. El año 2007, dictó además, la "Política de consolidación de la seguridad democrática", con el objetivo de desmantelar a las bacrim, lo que fue complementado por el Decreto 2374 del año $2010{ }^{37}$.

Quien fuera Alto Comisionado de la Paz en los años 2003-2006 y negociador con las AUC en "Justicia y Paz", Luis Carlos Restrepo, enfatizaba la distinción entre las llamadas bacrim y las antiguas formas de paramilitarismo. Afirmó que, "No son autodefensas lo que tenemos en el país son unas organizaciones criminales emergentes muy pequeñas que están manejando cultivos ilícitos que existían en las zonas donde se desmovilizaron las AUC"38. Mientras las AUC tuvieron presencia en 592 municipios, el accionar de las Bacrim el año 2010, marcaba una reducción del 69,8\% de presencia territorial.

Durante el segundo gobierno de Santos, y ante el crecimiento de la acción de los grupos armados, se impulsaron acciones legales y armadas para enfrentarlas. Entre las más importantes, se debe mencionar el Decreto $\mathrm{N}^{\circ} 2314$ del 1 de julio del año 2010 que creó una Comisión Interinstitucional integrada por 8 personas y presidida por el Ministro del Interior y Justicia, "contra las Bandas Criminales y se dictan disposiciones" 39 . Este decreto se fundamentó en el Plan nacional de Desarrollo 2006-2010 y en la Ley 1151 del 24 de Julio del 2007 artículo $6^{\circ}$ dentro del eje 2 de la "Política de Defensa y Seguridad Democrática" referido a garantizar el control del territorio y la defensa de la soberanía nacional a combatir el problema de las drogas, el crimen organizado y a promover una política de seguridad y convivencia ciudadana desde lo local" 40.

Estableció además, el llamado plan D-6 $6^{41}$ y operaciones militares exitosas como Troya Caribe (en Urabá y sur de Córdoba) y Troya Pacífico (en Cauca y Nariño). A cargo de las acciones dejó Santos al Ministerio de Defensa, quien el año 2016 emitió la Directiva Nº15 que tenía como objetivo hacer "uso máximo de la fuerza del Estado para combatir a grupos ilegales surgidos tras la desmovilización de las AUC"42.

El Gobierno promovió, además, el año 2016, una nueva caracterización del fenómeno atendiendo a su complejidad y diversidad. Así distinguió a los "Grupos Armados Organizados" o GAO, definidos como "organizaciones que bajo la dirección de un mando responsable ejerzan sobre una parte del territorio un control tal que les permita realizar operaciones militarmente sostenidas y concertadas" 43 . Por su parte, los Grupos Delictivos Organizados, GDO fueron definidos como una "estructura de 3 o más personas que existe durante cierto tiempo y que actué concertadamente con el propósito de cometer uno o más delitos graves" $"$.

\section{El paramilitarismo no ha terminado: Neoparamilitares, Narcoparamilitares}

No todos estaban de acuerdo con la visión y análisis del gobierno respecto a la desaparición del paramilitarismo en Colombia. Hubo intelectuales, académicos, ONGs y organizaciones internacionales que afirmaban que se estaba ante una nueva forma de paramilitarismo criminalizado. Para Soledad Granada, Jorge Restrepo, Alonso Tobón ${ }^{45}$, Frederic Massé ${ }^{46}$, y León Valencia los grupos armados post

37 García Ruiz María Andrea, Silva Aparicio Ángela María, Magallanes Montoya Marcela Julieth "Políticas para combatir a los grupos armados posdemovilización en los Gobiernos de Alvaro Uribe Vélez y Juan Manuel Santos” Análisis Político N92 Bogotá, Enero-Abril, 2018 PP 159-179.

38 Restrepo Luis Carlos en Fundación ideas para la Paz, FIP, octubre de 2015.

${ }^{39}$ Ministerio del Interior y Justicia, Decreto $N^{\circ} 2374$ de 1 de julio

40 Op. cit.

${ }^{41}$ Los 6 puntos son Desarticular, Desmantelar, Denegar, Disuadir, Direccionar, y Difundir.

42 www.verdadabierta.com/6269 del 12 de mayo de 2016.

43 Op. cit.

44 Op. cit.

45 Restrepo Jorge Granada Soledad y Tobón Alonso "Guerra y violencias en Colombia, herramientas e interpretaciones" Restrepo Jorge y Aponte David editores, Universidad javeriana de Colombia _CERAC, BogotaDC, 2009. 
AUC, eran una continuidad del paramilitarismo que tuvieron una desmovilización incompleta y se reestructuraron bajo formas del crimen organizado. Coinciden en que la desmovilización de las AUC tuvo un carácter parcial y "los mandos medios y sus reductos paramilitares persistieron y fueron el reservorio de las nuevas bacrim" 47 . Estas, han ampliado sus actividades económicas más allá del narcotráfico, incorporando a la minería del oro ${ }^{48}$. Estos grupos ya no son contrainsurgentes sino el "brazo armado de poderes mafiosos" o "mafias en armas".

A su vez, la "Defensoría del Pueblo", señaló que la desmovilización de las AUC derivó en un proceso de reorganización paramilitar. Estos mantuvieron sus funciones y objetivos de lucha contrainsurgente al mismo tiempo que intentaban hacer viables los objetivos económicos, operan bajo diversas denominaciones, en regiones y zonas estratégicas rentables. Las tres regiones del país con mayor presencia de los grupos armados de acuerdo a la Defensoría del Pueblo son Antioquía con el $29 \%$ del total, Córdoba 14\% y Cesar 9\%, es decir se trata de espacios geográficos que estuvieron bajo el control de las AUC en el pasado.

Para los académicos Carlos Medina Gallego, Gustavo Duncan, y Mauricio Romero, los grupos armados desde el 2006 son el resultado de procesos de mutación y transformación, del fenómeno paramilitar del siglo XX, son "grupos disidentes con vocación de control social y político local"49 que se han rearmado para realizar el copamiento de los territorios dejados por las AUC. No existió, afirman, una diferencia con las AUC, "estos últimos están más vinculados al narcotráfico y la explotación de recursos mineros o agropecuarios" 50 y con menor tono o ausencia de los objetivos contrainsurgentes, "no existe nada distinto entre bacrim y paramilitares son la misma cosa.

Los análisis reparaban en la disminución o eliminación de las motivaciones contrainsurgentes en los grupos armados. Para el "Instituto de Estudios sobre Paz y desarrollo", Indepaz, las nuevas estructuras armadas corresponden a formas más pequeñas y menos activas que las AUC y sin el ropaje contrainsurgente. Las denominó "narcopamilitares" u organizaciones de tipo "ejércitos privados", que buscan el control de medios y factores económicos para el enriquecimiento de sus líderes ${ }^{51}$, que en ocasiones se presentan como fuerzas del orden y protectores de megaproyectos ${ }^{52}$. Serían organizaciones armadas de tipo ilegal "cuyo objetivo central es el lucro de sus jefes e integrantes "53 los que además asumen funciones de orden público y contrainsurgentes en tanto sean necesarias para la realización de sus negocios.

Se coincidía en que se trataba de formas de paramilitarismo criminalizado, rearmado o reorganizado. Así por ejemplo, lo afirmaba el informe llamado "El rearme paramilitar" 54 del año 2011, del Centro de Estudios "Seguridad y Democracia" al dar cuenta que "donde la desmovilización de las AUC dejó un vacío de poder que ésta siendo copado por nuevas estructuras o formas recicladas de anteriores estructuras" 55 .

En el mismo sentido la "Comisión Nacional de Reparación y Reconciliación de Colombia", CNRR, en su segundo informe de julio del año 2010 señala que dentro de estos nuevos grupos armados "predomina la disputa de territorio y rutas del narcotráfico no se perfila un discurso político ni está prevista una ofensiva contra las guerrillas" 56 . Por su parte, la Organización de Estados

\footnotetext{
46 Mossé

47 Valencia León Op.cit pp 24-27

48 Op. cit.

49 www.verdadabierta.com "Bacrim, crimen organizado ¿Simples criminales o tercera generación de paramilitares?" 16 de enero de 2016/ 6146

50 Op. cit.

51 “Dejación de armas y sometimiento XIII Informe presencia de grupos narcoparamilitares" Indepaz primer semestre 2017.

52 Idem pag 2 y 3.

53 Indepaz XIII Informe Presencia de grupos narcoparamilitares Primer semestre 2017, Octubre 2017.

${ }^{54}$ www.verdadabierta.com/454-informe-especial-rearme-paramilitar-seg-ydemocracia

55 Op. cit. pp 12-13

${ }^{56}$ CNRR Segundo Informe Julio 2010.
} 
Americanos, OEA, a través de la misión de Apoyo al Proceso de Paz (MAPP/OEA) en su Sexto Informe de verificación del proceso de desmovilización de las AUC señaló que: "Se identificaron una serie de fenómenos armados posteriores a las desmovilizaciones entre los cuales se encuentra el reagrupamiento de desmovilizados en bandas delincuenciales" 57 y ejercen el control sobre comunidades, población, y las economías ilícitas. En síntesis, existió una amplia coincidencia entre los académicos y centros de estudio respecto a la prolongación del paramilitarismo, como una forma "degradada" de este, bajo la modalidad de narcoparamilitarismo. Sin embargo, el fenómeno armado, aun cuando tiene obvias herencias con el paramilitarismo no se corresponde con las definiciones más clásicas de este.

Por ejemplo, no tiene vinculaciones con partes del Estado como sus antepasados de las AUC, posee menor tonalidad contrainsurgente y carece de un plan de poder político. Otras diferencias, radican en su menor extensión nacional, su organización en redes y nodos a diferencia de las pretensiones jerárquicas y federativas de las Autodefensas. Hay una disolución de lo "político" en su accionar, el cual, ha sido reemplazado por actividades del tipo "criminalidad organizada". De acuerdo a la convención de las Naciones Unidas, las organizaciones del crimen organizado, son definidas como "un grupo bien estructurado de 2 o más personas de permanencia y actuación concertada con el propósito de cometer uno o más delitos" ${ }^{5}$. Sus operaciones se realizan a nivel transnacional, para lo cual establecen alianzas con los carteles mexicanos, principales actores hoy en día del negocio de las drogas.

\section{Actores delincuenciales transnacionales}

Un aspecto resaltante de las organizaciones post AUC es su accionar transfronterizo, a diferencia de las organizaciones criminales colombianas de las décadas de los 80 y 90 . A nivel oficial, el Gobierno de Colombia, reconoció la existencia de una criminalidad nacional que ha adquirido niveles de acción transnacional. Así, la canciller María Angélica Holguín, en su exposición ante los asistentes al 60 período ordinario de sesiones de la Comisión de estupefacientes de la ONU en Viena el lunes 13 de marzo del año 2017, dio cuenta de la presencia de organizaciones criminales como el Cartel de Sinaloa, en el bajo Cauca y el Catatumbo: "con enormes sumas de dinero para garantizar la compra de la hoja de coca, ya no estamos enfrentando sólo carteles colombianos sino también extranjeros" 59 .

A nivel jurídico, hay también denuncias provenientes de la Defensoría del Pueblo y del Fiscal General, acerca de las vinculaciones de las organizaciones criminales colombianas con carteles de la droga mexicanos. En ese sentido, el Defensor del Pueblo Carlos Negret alertó al Gobierno respecto de que; "En Tierralta, Departamento de Córdoba (zona de hegemonía en el pasado de las AUC), ha estado actuando supuestamente el Cartel de Sinaloa que es el que financia bandas como las Autodefensas Gaitanistas"60. Por su parte, el Fiscal General Néstor Humberto Martínez señaló que los carteles mexicanos ya empezaron a adquirir plantaciones de coca en Colombia, "hemos capturado a agrónomos e ingenieros de ese país que están mejorando en laboratorios la productividad de la planta" ${ }^{1}$. Uno de los carteles mexicanos, más activos y con mayor presencia en Colombia, de acuerdo a las informaciones oficiales, sería el de Sinaloa, que tendría 6 oficinas en Colombia, localizadas en Tumaco, Cali, Bucaramanga, Cartagena y Medellín. El registro oficial de la Fiscalía, sostiene que hay

${ }^{57}$ www.mapp-oea.org Sexto informe de verificación doc. 4075/06 del 16 de febrero del 2006.

58 Caviedes Estanislao Escalante-Barreto "Crimen organizado y problemas dogmáticos de autoría y participación: Análisis comparado de Colombia y España en el marco del delito contra el delito en la ONU” pp105, Revista Pensamiento Jurídico N ${ }^{\circ}$ 45, Universidad Nacional de Colombia 2017.

${ }^{59}$ www.cancilleria.gov.co, del 12 de marzo de 2017.

${ }^{60}$ www.elcolombiano.com.co "Cartel de Sinaloa estaría financiando bandas criminales en Colombia" 20 de enero de 2016.

${ }^{61}$ www.eltiempo.com "En estos diez departamentos hacen presencia Carteles mexicanos "Unidad Investigativa del 29 de enero de 2018. 
presencia de este cartel en 9 departamentos del país, "Cundinamarca, Norte de Santander, Valle del Cauca, Nariño, Meta, Guaviare y Vichada todos ellos de alta producción de coca y activa presencia de las Bacrim"62.

Control territorial, de la población y capitalismo criminalizado. La implementación de la violencia para mantener el control territorial y de la población, es un rasgo propio de las organizaciones del crimen organizado que operan en distintos escenarios latinoamericanos, como los carteles mexicanos, el asociado al tráfico de drogas de Brasil y las "clicas" de la Mara "Salvatrucha" de El Salvador ${ }^{63}$ quienes ejercen un "dominio armado" " ${ }^{64}$ del territorio. En ese sentido, se ubican los llamados "Paros armados" llevados a cabo por las "Autodefensas Gaitanistas de Colombia”, brazo armado del "Clan del Golfo", que lograron detener las actividades de 6 departamentos el año 2012 y 8 el 201465. El año 2016, el "paro armado" se desarrolló en 36 municipios del país, y, según la Policía Nacional, el 63\% de los actos de fuerza afectó a la población. Los departamentos más afectados son Antioquía, Chocó, Córdoba y Sucre ${ }^{66}$.

Estudios como el de Ávila y Valencia, parecen indicar que las actividades desplegadas por las organizaciones criminales más poderosas, al igual que las AUC, encuentran algún nivel de apoyo en clanes políticos, de tipo mafioso. Ello, en regiones donde hubo predominio paramilitar como el Departamento de Bolívar, donde, aún después de la desmovilización y encarcelamiento de parapolíticos, se han mantenido ${ }^{67}$.

Nuevas orgánicas. Estas entidades, se configuran a partir de redes y nodos. Esta, es una gran diferencia de organización interna respecto de estructuras criminales anteriores tales como los cárteles de las drogas y los paramilitares. En este nuevo esquema, las organizaciones de mayor capacidad militar someten o cooptan a las menores, venden franquicias a bandas y pandillas urbanas, configurando un diseño de flexibilidad del tipo empresarial pero criminal. Un ejemplo de la nueva modalidad orgánica es el poderoso "Clan del Golfo", que se impuso sobre las otras organizaciones criminales de Colombia hacia el año 2015. Estos, se consolidaron como "un Nodo en el mercado ilegal del Narcotráfico y una organización de tercera generación que funciona en red con nodos territoriales y donde los mandos son reemplazables fácilmente" 68 . En el mando superior, se ubica una "mesa directiva" compuesta por 5 personas que cubren un territorio amplio, seguidos de los llamados "socios" o" 50 mandos, cada uno con un territorio asignado por su Jefe" 69 A su vez, los mandos contribuyen con dinero para financiar a la fuerza militar llamada "Autodefensas Gaitanistas de Colombia", fuerza de choque encargada de la seguridad de los jefes y de las operaciones armadas contra competidores como "Los Rastrojos". En los territorios a su cargo, buscan replicar la gobernanza de las AUC. Así, por ejemplo, ejercen la Justicia a través un Comandante político y otro militar encargados de recoger denuncias, tramitar pruebas y ejecutar las sanciones y penalidades. Cobran también impuestos a comerciantes locales, usando para ello la extorsión y la violencia.

La organización, está compuesta por un centro y periferias con actividades y composición distintas, que las hace resistente a la acción policial. El centro toma las decisiones importantes (Estado

\footnotetext{
62 Se trataría señala de los Carteles de los Zetas, Sinaloa y Jalisco Nueva generación. En la actualidad existen 102 investigaciones que vinculan a 103 ciudadanos mexicanos.

63 Savenije Wim "Las pandillas transnacionales o "maras" violencia urbana en Centroamérica" Foro Internacional Jul-Sept N47 Sept. 2007 PP 637-659 Colegio de México.

${ }^{64}$ Miranda Ana Paula "Dominio armado, el poder territorial de las facciones. Los comandos y las milicias en Río de Janeiro " www.vocesenelfenix.com, pp 44-49, Universidade Federal Fluminense. 2018.

${ }^{65}$ www.verdadabierta.com "Urabeños demuestran su poder regional" 5 de enero de 2012.

${ }^{66}$ www.elespectador.com "Paro armado se vivió en 36 Municipios del país" 1 de abril de 2016.

${ }^{67}$ Valencia León- Ávila Ariel “Herederos del Mal clanes, mafias y mermelada Congreso 2014-2018” Página 248, Grupo Zeta, Bogotá, 2014

68 Fundación Paz y Reconciliación "La compleja estructura del Clan del Golfo” 16 de julio de 2018.

${ }^{69}$ Fundación Paz y Reconciliación "La compleja estructura detrás del Clan del Golfo” 16 de julio de 2018.
} 
Mayor) mientras que las periferias son flexibles y actúan en terreno, cumpliendo parte de las tareas propias del narcotráfico, sicariato, oficina de cobros, vigilancia privada y extorsiones. La periferia puede estar constituida por bandas ya existentes de menor tamaño, las cuales son tercerizadas tipo "outsourcing", en una modalidad de "posfordismo" criminal que les proporciona gran capacidad operativa y comunicaciones internas más fluidas.

Un actor económico criminalizado. La desmovilización incompleta de las AUC, la tardanza en la llegada del Estado a los territorios a través de políticas sociales y desarrollo, sumado al incremento del narcotráfico y la minería ilegal, confluyeron para la conformación de numerosas y fragmentarios grupos armadas a partir del año 2006. Lo anticipó Rodrigo Tovar Pupo alias "Jorge 40" líder del Bloque Norte de las AUC, al señalar que "Si el Gobierno no cumple, es claro que surgirán nuevos grupos armados como respuesta a la indiferencia y el olvido del Estado"70.

Las bases productivas que permiten el funcionamiento y enriquecimiento de las organizaciones post AUC, se realizan en ámbitos económicos con debilidades institucionales, que llamaremos "espacios ingobernados". Según el departamento de las Naciones Unidas dedicado al estudio del mercado de las drogas, UNOCD, en estas regiones se concentra el 51\% del cultivo de drogas de Colombia ${ }^{71}$. Entre las actividades económicas, más importantes señalamos a la minería del oro. Esta actividad extractiva, se desenvuelve dentro de la ilegalidad en Colombia. Una investigación de la Contraloría General dirigida por Jorge L. Garay, señala que el 63\% de la explotación de oro es ilegal en el país ${ }^{72}$. La Asociación colombiana de minería por su parte, reveló que, en el año 2016, Colombia produjo 1,99 millones de Onzas troy, de estas sólo el 13\% venían de explotaciones formales, siendo Antioquia el mayor productor. La producción y las reservas de oro de Colombia son de gran magnitud. Se estima que estos yacimientos tienen reservas probadas de 7 millones de onzas, vale decir, unas 141 toneladas de oro ${ }^{73}$.

Mientras tanto, sigue siendo el narcotráfico el negocio de mayor rentabilidad y tradición criminal de Colombia, y logra concitar en pos de su control a integrantes de estructuras armadas de todo tipo, paramilitares, disidencias guerrilleras, al mismo tiempo que genera recursos para el funcionamiento de organizaciones ilegales. El crecimiento de los cultivos ha dejado en evidencia el fracaso de los planes de erradicación. Este incremento ha incluido a los territorios étnicos y parques nacionales donde por la legislación ambiental, está prohibida la fumigación ${ }^{74}$ o la implementación de programas para la de sustitución de cultivos ${ }^{75}$. Las áreas cultivadas, han ido aumentando desde el año 2013, para alcanzar los records de 150 mil hectáreas el 2016 y más de 200 mil en 2017. De acuerdo al trabajo de Echandía ${ }^{76}$ ha existido históricamente, una convergencia de las organizaciones armadas en zonas de narcotráfico, y este se ha mantenido en los continuadores de las AUC.

El contrabando, es también una actividad de alta rentabilidad. En primer lugar, de Combustibles. De acuerdo con la Fundación Ecopetrol, el tráfico ilegal recorre la ruta que va desde Monte Lara a Maicao, en La Guajira, y Bodillo y Río Seco, en Valledupar, desde donde se distribuye luego a Magdalena y Sur de Bolívar. Existen tres tipos de contrabando de combustible "los pimpineros", corresponde a la actividad realizada por personas que venden botellas llenas de gasolina, la "Caravana de la muerte" que realizan grupos de 10 a 20 vehículos y finalmente está el gran comercio o "gran contrabando que se realiza en camiones cisterna hasta los departamentos de Antioquia y

\footnotetext{
70 En www.semana.com "Habla Jorge 40", 26 de septiembre del 2008.

71 Rico Daniel "Las dimensiones internacionales del crimen organizado en Colombia, las bacrim, sus rutas y refugios".

72 "La minería criminal va a generar más violencia” José L. Garay en www.eltiempo.com 11 de mayo de 2013.

${ }^{73}$ En el mercado internacional una onza troy de oro se cotiza a 1.293 dólares

${ }^{74}$ Hay que considerar que la fumigación con químicos como el glifosato fueron prohibidos el año 2015, debido a los informes de efectos dañinos para las personas presentados por la OMS.

75 www.semana.com "La coca se dispara", edición del 5 de marzo de 2017.

${ }^{76}$ Echandía Camilo Op. cit.pp.23-26
} 
Boyacá. Cada año entran al país más de 100 millones de litros de gasolina ${ }^{77}$ y las autoridades señalan que cada día ingresan de manera ilegal cerca de tres millones de dólares en combustibles.

Por su parte, el Contrabando de Aluminio es otra modalidad de economía ilegal. Según la División de Impuestos y Aduanas de Colombia se ha incrementado el contrabando de aluminio proveniente de Venezuela el año 2017 en un 629\%. En ese país, es adquirido por contrabandistas a 2500 pesos el kilo para ser luego vendido en Colombia en 4500-5000 pesos, todo el negocio está bajo el control de las organizaciones señalas en este trabajo ${ }^{78}$. A estas actividades económicas, se deben agregar el cobro de extorsiones a comerciantes y empresas, el microtráfico, arrendamiento de seguridad, y el papel de las oficinas de cobro. Las organizaciones post AUC, son una modalidad del crimen organizado transnacional. Teóricamente consideramos al "crimen organizado" como una expresión ilegal de fuerza, distinta a la "criminalidad común”. El crimen organizado, busca establecer el control de toda la estructura económica de la ilegalidad mediante prácticas violentas y a través de estructuras organizadas bajo la forma de empresas. Diego Gambetta, describe tres funciones que son propias del crimen organizado: ofrecimiento de seguridad privada ilegal, resolución de conflictos y apropiación de rentas en mercados ilegales ${ }^{79}$. Al revisar las fuentes relativas a la actuación de los grupos armados, se podrá concluir que todas las características referidas por el autor italiano están presentes, ofrecen servicios de seguridad a embarques de drogas o laboratorios y resuelven conflictos en el campo político y económico, usando la violencia.

Las formas de criminalidad consideradas, perfilan a un actor económico del capitalismo colombiano que aprovecha la ausencia de un empresariado que lidere e impulse actividades económicas a partir de bases capitalistas modernas y externalidades económicas positivas en regiones de "frontera interna" e ingobernadas y aprovechan las condiciones de pobreza de la población. Algunas industrias y empresarios lograron manejar el ambiente hostil, haciendo pagos a los bandos en conflicto en los años 90 y primera década del siglo XXI, la estadounidense "Chiquita Brands". Esta multinacional con sede en Cincinatti, que se dedica a la producción y comercialización del banano, hizo pagos a las guerrillas y las AUC entre 1990-2006, para poder continuar con sus operaciones. Las empresas y empresarios que no pudieron hacer lo mismo, sucumbieron a la guerra y abandonaron las actividades productivas.

El papel como actores de la economía de las organizaciones criminales es analizado en los trabajos de Daron Acemoglu ${ }^{80}$, para la mafia siciliana, los paramilitares y guerrillas de Colombia. Afirma que, en el mediano y largo plazo las organizaciones criminales, afectan la acción política, del estado, el desarrollo económico y los procesos democráticos eleccionarios. En efecto, la extorsión y la violencia contribuyen al atraso económico y la pobreza. Por una parte, hacen imposible promover instituciones de crédito, tecnologías productivas, modernas relaciones sociales y del trabajo, al mismo tiempo que promueven rigideces económicas insuperables y estructuralmente instaladas en regiones ricas en recursos naturales. Las organizaciones criminales actualmente existentes, impulsan un diseño económico de alta rentabilidad, de propiedad privada en los medios de producción. Esta ha sido obtenida por la compra o apropiación violenta, como ocurre por ejemplo con la tierra. Acorde al capitalismo moderno, desarrollan formas de trabajo que combina el uso intensivo como en la minería o en fases de la cadena del narcotráfico con el flexible o informal como en el sicariato o el microtráfico. En un símil criminal de "desfragmentación productiva", las organizaciones colombianas, controlan los ámbitos económicos donde se garantiza el mayor valor del bien, como en la producción y elaboración

\footnotetext{
${ }^{77}$ www.verdadabierta.com / .../search/?../los\%20 urabeños"

${ }^{78}$ www.elpais.com.co "Venezuela crimen sin frontera", en Venezuela-crimen-sin-frontera / home.

${ }_{79}$ Gambetta Diego "La mafia siciliana: el negocio de la protección privada” Fondo de Cultura Económica, México, 2007.

80 Acemoglu Daron, De Feo Giuseppe, Giocomo Lucía “'The monopoly of violence :evidence Weak States, Causes and consequences of the Sicilian mafia" Journal of Economic Asociation Nov. 2017.

Acemoglu Daron, Robinson A. James, Santos Rafael “The Monopoly of violence: Evidence from Colombia” Journal of the European Economic Association, Volume 11, issue suppl_1,1 jan. 2013.
} 
de la cocaína, externalizando la distribución del producto para cubrir de modo eficiente y especializado la oferta global.

Configuran paralelamente, un proceso económico, similar al analizado por Arroster y Soares ${ }^{81}$ para "Magoney Trade" en la Amazonía brasileña, donde los derechos de propiedad o el cumplimiento de los contratos, se realizan fuera del marco jurídico formal, y a través del uso de la fuerza.

Toda esta acción económica, provoca impactos territoriales, ambientales y macroeconómicos. Por ejemplo, interviene en los precios de los productos ilegales maximizando la tasa de ganancia, vigilando cargamentos, cooptando aduanas, policías, instituciones. Así mismo, producen relaciones de clientelismo-coerción con la población, a través del empleo, los ingresos, la protección, el sometimiento, el convencimiento o el miedo. Consiguen de ese modo, un activo social que les es propicio para diversas tareas de la organización, como obtener la información necesaria en beneficio de sus actividades y la producción-comercialización de mercancías. Al mismo tiempo, las provee de integrantes para sus grupos armados.

Por otra parte, contribuyen a aumentar las desigualdades en torno a la distribución de la riqueza a nivel de la periferia de Colombia. Así, en poblaciones pobres, algunos "señores de la violencia" y las armas atesoran millones de dólares, consolidando una asimetría económica que, a la par y dialécticamente, causa descompensaciones a nivel político. La riqueza que se genera por actividades como el narcotráfico, inhibe la diversificación productiva. Por ejemplo, por una hoja de coca, el cultivador recibe una ganancia por hectárea de 1.300 .000 pesos en promedio cada dos meses: "con un producto cuyo servicio es 'puerta a puerta' y tiene una enorme demanda." $82 \mathrm{~A}$ modo de comparación, un campesino que produce cacao recibe por cada hectárea 160 mil pesos al mes. ${ }^{83}$ Las organizaciones criminales participan de las fases intermedias de la cadena del narcotráfico en tareas como: "compra de la pasta base producción de clorhidrato, custodia y embarque, control del microtráfico de consumo interno" 84 .

Durante la posguerra fría, década de los 90, las amenazas a la paz provinieron de actores no estatales fortalecidos por el control de economías ilegales y que operaban en un contexto donde el Estado ha visto disminuido el monopolio de la fuerza. ${ }^{85}$ En la globalización, las amenazas han provenido del terrorismo, el fanatismo religioso, étnico y del crimen organizado. Con ello, las contiendas han dejado de tener un carácter interestatal para pasar a ser "conflictos intraestatales de baja intensidad" "86. El año 1995, la Organización de las Naciones Unidas identificó 18 categorías de "delitos transnacionales" incluyendo en el listado el lavado de dineros, las actividades terroristas, el robo de propiedad intelectual, cibercrimen, corrupción y narcotráfico entre otros ${ }^{87}$.

La internacionalización de las organizaciones criminales en Colombia no es un fenómeno nuevo. Se puede señalar como inicio de este, el accionar de los carteles de la cocaína en los años 80 y el control del negocio por las AUC en los años 90 e inicios del siglo XXI. En ese período, la internacionalización de las organizaciones criminales apuntó a tres objetivos: La adquisición de armas y tecnología, la expansión y reconversión de utilidades y el ejercicio de violencia fuera de las fronteras ${ }^{88}$.

\footnotetext{
81 Arroster Cimeli y Soares Rodrigo "The use of violence in ilegal markets, evidence from Mogohay Trade in the Brazilian Amazon” Revista IZADP N 5923 August 2011, Germany.

82 www.semana.com "Coca ¿pelea de tigre con burro armado? "edición del 11/11/2017.

83 Op. cit.

84 Prieto Carlos Andrés "Las Bacrim y el crimen organizado en Colombia” Fes Seguridad, marzo 2013, Bogotá.

85 Kaldor Mary "New and old Wars organized violence in a global era" Polity Press pp. 1-15, Cambridge CB2 IUR, IK 2012 ISBN-13 978-0-7456-5562-8

86 Linares Hamann Jorge Enrique "Redes criminales transnacionales, Principal amenaza para la seguridad internacional en la posguerra fría "Revista Criminalidad Vol. 50, Nº1, pp. 371-384 ISSN: 1974-3108, mayo 2005.Ver también Kaldor Mary "New and old Wars organized violence in a global era" Chapter five "The globalized war economy" pp 94-119, third edition, Polity Press, Cambridge UK 2012.

87 UNO ODCCP 1999 “Global report Crime and Justice” New York Oxford University Press.

${ }^{88}$ Rico Daniel "Las dimensiones internacionales del crimen organizado en Colombia, las bacrim sus rutas y refugios"
} 
El crimen organizado tradicional de los años 80 e inicios de los 90, tenía efectos transfronterizos limitados, movimientos controlados de personas o bienes y el intercambio de información era poco frecuente ${ }^{89}$.

En el marco de la globalización, en cambio, las estructuras paramilitares y sus continuadoras pueden ser caracterizados como "un grupo de delincuentes que aúna fuerzas para llevar a cabo un delito específico, es similar a una empresa en la que todos desempeñan simplemente su parte de manera organizada" 90 , que han mejorado la eficiencia de sus actividades delictivas a través de estructuras delictivas transnacionales, "significativamente armadas que desarrollan tareas de control de los grandes negocios ilícitos como depredación subsidiaria de los mismos" "11. La globalización ha facilitado el intercambio de bienes ilícitos, "y la consolidación de alianzas entre organizaciones criminales de todo el mundo"92. En la búsqueda de nuevos mercados y la necesidad de huir de la efectiva acción policial han desarrollado la llamada "migración criminal", o "trasplante criminal", que consiste en el traslado de las organizaciones a nuevos espacios geográficos desprotegidos y asociados a extensos conflictos armados.

Las organizaciones post AUC son actores "transnacionales", protagonistas de importancia para el orden internacional. Hay trabajos periodísticos y académicos que han fijado su interés en el carácter transfronterizo del quehacer económico de estos grupos y bandas. Por ejemplo, Jeremy Mac Dermott, (2014) ${ }^{93}$ identifica a las bandas criminales como la tercera generación del narcotráfico de Colombia, quienes participan en las fases intermedias de la cadena del narcotráfico, en la compra de pasta base, la producción de clorhidrato, la custodia y embarque de producción, y el control del microtráfico orientado al consumo interno ${ }^{94}$. Por su parte, el análisis de Carlos Andrés Prieto ${ }^{95}$ aborda el carácter global de estas organizaciones desde dos dimensiones: las rutas que utilizan las organizaciones para realizar el negocio del narcotráfico y el carácter de amenaza para la paz de la región.

El accionar de las organizaciones delictivas colombianas, se ha consolidado más allá las fronteras, hacia el Norte. Han sobrepasado los $2219 \mathrm{Km}$ del límite con Venezuela y abierto más de 200 "trochas" para el desarrollo de actividades como el contrabando de combustibles, narcotráfico y aluminio ${ }^{96}$. En síntesis, proponemos mirar a las entidades post AUC más allá de sus continuidades o rupturas con el paramilitarismo del que provienen. Es importante, considerarlos como un actor económico capitalista de tipo criminal y carácter transnacional que se nutre de protagonistas y violencias de cinco décadas de conflicto interno.

\section{Conclusión}

La investigación se ha desarrollado con el objetivo de pensar los procesos históricos recientes de América del Sur, en un contexto de violencia política en sus actores paraestatales. Nuestro tema de investigación se centró temporalmente el año 2006, luego de la desmovilización de las AUC. Entonces,

\footnotetext{
89 Linares Hemann Jorge Enrique "Redes criminales transnacionales principal amenaza para la seguridad internacional post guerra fría” Estudios criminológicos Vol 50, Nº1, págs. 371-384.

90 Gambetta Diego "La mafia siciliana, el negocio de la protección privada" Fondo de Cultura Económica, México 2010 página 371.

91 Aldemar Francisco, Zamora Franco y Suárez Venegas Juliana "Bandas Criminales "Observatorio de Derechos Humanos 2011 y en Michael Reed "Bacrim trampa conceptual " www.elcolombiano.com edición del 4 de abril de 2011

92 Linares Hamann Op. cit. pp. 374

93 Mac Dermontt Jeremy "El rostro cambiante del crimen organizado" Perspectivas 9/ 2014, FES Seguridad, Bogotá.

94 Tickner Arlene "La securitización de la crisis colombiana, bases conceptuales y tendencias generales" pp. 424, Revista Colombiana Internacional Nº6, Departamento de Ciencia Política Universidad de los Andes.

95 Prieto Carlos Andrés "Bandas criminales en Colombia ¿amenaza para la seguridad regional? Opera No 12, Redalyc.org Sistema de Información Científica

${ }^{96}$ www.verdadabierta.com y www.elpais.com.co /especiales/ "Venezuela-crimen-sin frontera/home. Diario El País de Cali.
} 
se evidenció el accionar de organizaciones armadas en espacios geográficos que estuvieron bajo el dominio paramilitar.

No tuvieron la misma relación con el Estado que los paramilitares clásicos y su interés político era menor y subsidiario de sus intereses. La reacción de la institucionalidad combinó modos legales y acciones represivas y se concentró a partir del año 2010. Hubo innegables éxitos policiales y de recuperación de la potestad del Estado.

Sin embargo, no ocurrió igual con otros aspectos institucionales como las políticas sociales, planes de empleo, alternativas a la erradicación de cultivos, planes de infraestructura o conectividad, que se encuentran aún al debe en espacios "de frontera" de Colombia.

Las organizaciones criminales, conforman un actor económico que afecta el desarrollo, el logro la equidad social y la legalidad. Desarrollan operaciones tendientes al control de la oferta de bienes, eliminación o sumisión de competidores, establecen alianzas con carteles mexicanos, abren nuevos mercados, y producen el lavado de activos en un escenario global. Son en síntesis actores económicos del capitalismo colombiano, fuerzas transnacionales de tipo criminalidad organizada, y no corresponden a la visión clásica, teórica e histórica del paramilitar vinculado de algún modo al estado y la contrainsurgencia. Despliegan eficiencia operativa a partir de novedosas formas orgánicas de mayor flexibilidad y resistencia a la acción policial. Por su versatilidad son un riesgo permanente para la convivencia social, el Estado, la democracia, el desarrollo, la equidad y para la sociedad global.

Hemos establecido, que para considerar integralmente a las organizaciones y grupos armados post AUC, debemos entenderlas y analizarlas como partes de la histórica privatización de la violencia colombiana y del conflicto interno, del paramilitarismo, su accionar político y/o delictivo. Finalmente, se pueden caracterizar, desde su papel de actor económico flexible y adaptable a los cambios de la economía, la acción del estado y la sociedad internacional. También, por su accionar transnacional y por la configuración de un capitalismo de carácter criminal de alta rentabilidad. El trabajo demuestra nuestra hipótesis de que los conflictos internos extendidos en el tiempo, sumados al incremento de economías ilícitas y fracasos institucionales sumado a la tardanza del Estado para hacer presencia institucional en regiones de control paramilitar, confluyen a la continuidad criminalizada de actores armados que alguna vez sostuvieron algún nivel de motivaciones políticas, aunque estas no fueran parte de toda la organización.

\section{Bibliografía}

\section{Libros}

- Aldemar Francisco, Zamora Franco y Suárez Venegas Juliana "Bandas Criminales "Observatorio de Derechos Humanos 2011 y en Michael Reed "Bacrim trampa conceptual “ www.elcolombiano.com edición del 4 de abril de 2011.

- Acemoglu Daron, De Feo Giuseppe, Giocomo Lucía “"The monopoly of violence: evidence Weak States, Causes and consequences of the Sicilian mafia" Journal of Economic Asociation Nov. 2017.

- Acemoglu Daron, Robinson A. James, Santos Rafael "The Monopoly of violence :Evidence from Colombia” Journal of the European Economic Association, Volume 11, issue suppl_ 1,1 jan. 2013.

- Arroster Cimeli y Soares Rodrigo "The use of violence in ilegal markets, evidence from Mogohay Trade in the Brazilian Amazon" Revista IZADP N 5923 August 2011, Germany.

- Cepeda Iván- Rojas Jorge "A las puertas de El Ubérrimo, El origen del paramilitarismo y la parapolítica en Córdoba” Ediciones B Colombia S.A. 2014.

- Cubides Fernando "Los paramilitares y su estrategia”, Ediciones Uniandes, Bogotá 1999, pp 151-159.

- Duncan Gustavo "Los Señores de la Guerra, De paramilitares, mafiosos y autodefensas en Colombia” Debate, Bogotá DC, Colombia 2010. 
- Echandía Camilo "Narcotráfico génesis de los paramilitares y herencia de bandas criminales" Fundación Ideas para la Paz, 6 de febrero de 2013.

- Gambetta Diego "La mafia siciliana, el negocio de la protección privada" Fondo de Cultura Económica, México 2010 página 371.

- Garay Salamanca Luis Jorge (Dirección académica) "La captura y reconfiguración cooptada del Estado en Colombia" Corporación Transparencia por Colombia 2008, pág.16. También en World Bank XV, 2000.

- García Ruiz María Andrea, Silva Aparicio Ángela María, Magallanes Montoya Marcela Julieth "Políticas para combatir a los grupos armados posdemovilización en los Gobiernos de Alvaro Uribe Vélez y Juan Manuel Santos” Análisis Político Nº2 Bogotá, Enero-Abril, 2018 PP 159-179.

- Gonzalez Camilo "El complejo paramilitar se transforma” Indepaz, Bogotá, Colombia, 2017.

- Hobsbawm Eric "Rebeldes Primitivos”, Editorial Ariel, Barcelona, 1983. “iViva la Izquierda!" Editorial Crítica, Barcelona, 2018.

- Kaldor Mary "New and old wars organized violence in the global era" Polity Press Cambridge CB 21 UR, UK 2012.

- Kalyvas Statis- Arjona Ana "Paramilitarismo: Una perspectiva histórica" en "El Poder Paramilitar" Alfredo Rangel edición y prólogo, Planeta, Bogotá 2005

- Linares Hemann Jorge Enrique "Redes criminales transnacionales principal amenaza para la seguridad internacional post guerra fría" Estudios criminológicos Vol 50, Nº1, págs. 371-384.

- López Claudia (Edición) "Y refundaron la Patria...De como mafiosos y políticos reconfiguraron el Estado colombiano" Corporación Nuevo Arco Iris, Congreso, Visible, De Justicia, Grupo Método, Bogotá, 2010.

- Mac Dermontt Jeremy "El rostro cambiante del crimen organizado" Perspectivas 9/ 2014, FES Seguridad, Bogotá.

- Medina Gallego Carlos y Téllez Ardila "La violencia Parainstitucional, paramilitar y parapolicial en Colombia” Rodríguez Quito Editores, Bogotá Colombia, 2004.

- Medina Gallego Carlos "Mafias, Narcotráfico, y bandas criminales en Colombia, elementos para un estudio comparado con el caso mexicano" Universidad Nacional de Colombia, 2017.

- Marco Palacios "Violencia pública en Colombia 1958-2010 "Capítulo III "Guarra a las drogas, escalamiento y guerra sucia” Fondo de Cultura Económica, Bogotá, Colombia, 2012.

- Miranda Ana Paula "Dominio armado, el poder territorial de las facciones. Los comandos y las milicias en Río de Janeiro" www.vocesenelfenix.com, pp 44-49, Universidade Federal Fluminense. 2018.

- Pécaut Daniel “En busca de la nación colombiana”, Debate, Colombia, 2017.

- Prieto Carlos Andrés "Bandas criminales en Colombia ¿amenaza para la seguridad regional? Opera $\mathrm{N}^{\circ}$ 12, Redalyc.org Sistema de Información Científica.

- Prieto Carlos Andrés "Las Bacrim y el crimen organizado en Colombia” Fes Seguridad, marzo 2013, Bogotá.

- Renouvin Pierre "Historia de las Relaciones Internacionales" Tomo I, Akal, España, 1990. Renouvin Pierre y Duroselle Jean Baptiste " La introducción a la Historia de las Relaciones Internacionales" Fondo de Cultura Económica, España, 2001

- Restrepo Jorge Granada Soledad y Tobón Alonso "Guerra y violencias en Colombia, herramientas e interpretaciones" Restrepo Jorge y Aponte David editores, Universidad javeriana de Colombia CERAC, Bogota DC, 2009.

- Rico Daniel "Las dimensiones internacionales del crimen organizado en Colombia, las bacrim sus rutas y refugios" 
- Trejos, Kalyvas y Ana Arjona "Paramilitarismo una perspectiva histórica "en "El Poder Paramilitar "Alfredo Rangel Editor y prólogo, pp 25-41, Planeta Colombia, 2005.

- Tickner Arlene "La securitización de la crisis colombiana, bases conceptuales y tendencias generales" pp. 424, Revista Colombiana Internacional N60, Departamento de Ciencia Política Universidad de los Andes.

- Valencia León- Ávila Ariel "Herederos del Mal clanes, mafias y mermelada Congreso 2014-2018” Página 248, Grupo Zeta, Bogotá, 2014

- Revista "Cambio", "Reciclaje Para” Edición N 676 del 12 de junio del año 2006.

\section{Revistas}

- “Basta Ya! Colombia: memorias de guerra y dignidad” Centro Nacional de Memoria Histórica pág.36 Bogotá, 2012

- Caviedes Estanislao Escalante-Barreto "Crimen organizado y problemas dogmáticos de autoría y participación: Análisis comparado de Colombia y España en el marco del delito contra el delito en la ONU” pp105, Revista Pensamiento Jurídico N 45, Universidad Nacional de Colombia 2017.

- "Crimen organizado y Saboteadores en tiempos de transición "Fundación Ideas para la Paz, FIP; Serie Informes N²7/ Julio 2017 ISBN 978-958-5978-7-5

- García Patricio "Las Autodefensas Unidas de Colombia (AUC) 1994-2005 “.Historia de un actor estatal, antisubversivo y de alcance transnacional en el conflicto interno" Capítulo IV páginas 163176,Tesis para optar al Grado de Doctor en Historia, Depto. de Historia, Universidad de Santiago de Chile, 2016.

- García Patricio "La privatización de la violencia en Colombia y las AUC: de las autodefensas al paramilitarismo criminal y contrainsurgente" Revista Izquierdas, № 27 abril de 2016 E-ISSN 07185049.

- Gibson Edward "Subnational Authoritarianism Territorial Strategies of Political control in Democratic Regimes", Northwestern University, September 25, 2004 en López Claudia "Y refundaron la patria.... De cómo mafiosos y políticos reconfiguraron el Estado colombiano" Debate, Bogotá DC,Colombia, 2010

- Savenije Wim "Las pandillas transnacionales o "maras" violencia urbana en Centroamérica" Foro Internacional Jul-Sept N47 Sept. 2007 PP 637-659 Colegio de México.

- UNO ODCCP 1999 "Global report Crime and Justice” New York Oxford University Press.

- Valencia León "Las Bandas Criminales y el postconflicto” Fundación Paz y Reconciliación, 24 de febrero de 2016.

\section{Páginas web}

- www.inSigthcrime.org

- www.verdadabierta.com

- www.vocesenelfenix.com, pp 44-49, Universidad Federal Fluminense. 2018.

- www.defensoria.gov.co

- www.semana.com

- www.mapp-oea.org.

- $\quad$ www.elespectador.com.co

- www.elpais.com.co

- www.eltiempo.com

- www.elcolombiano.com.co

- www.cancilleria.gov.com 